\title{
Classification and identification of bacteria by Fourier-transform infrared spectroscopy
}

\author{
D. Helm, ${ }^{1 *}$ H. Labischinski, ${ }^{1}$ Gisela SchallehN ${ }^{2}$ and D. NaumanN ${ }^{1}$ \\ ${ }^{1}$ Abteilung für Cytologie, Robert Koch-Institut des Bundesgesundheitsamts, Nordufer 20, D-1000 Berlin 65, Federal Republic \\ of Germany \\ ${ }^{2}$ Institut für Medizinische Mikrobiologie und Immunologie der Universität, Bonn, Federal Republic of Germany
}

(Received 3 April 1990; revised 29 August 1990; accepted 4 September 1990)

\begin{abstract}
This study describes a computer-based technique for classifying and identifying bacterial samples using Fouriertransform infrared spectroscopy (FT-IR) patterns. Classification schemes were tested for selected series of bacterial strains and species from a variety of different genera. Dissimilarities between bacterial IR spectra were calculated using modified correlation coefficients. Dissimilarity matrices were used for cluster analysis, which yielded dendrograms broadly equated with conventional taxonomic classification schemes. Analyses were performed with selected strains of the taxa Staphylococcus, Streptococcus, Clostridium, Legionella and Escherichia coli in particular, and with a database containing 139 bacterial reference spectra. The latter covered a wide range of Gram-negative and Gram-positive bacteria. Unknown specimens could be identified when included in an established cluster analysis. Thirty-six clinical isolates of Staphylococcus aureus and 24 of Streptococcus faecalis were tested and all were assigned to the correct species cluster. It is concluded that: (1) FT-IR patterns can be used to type bacteria; (2) FT-IR provides data which can be treated such that classifications are similar and/or complementary to conventional classification schemes; and (3) FT-IR can be used as an easy and safe method for the rapid identification of clinical isolates.
\end{abstract}

\section{Introduction}

Fourier-transform infrared (FT-IR) spectra of bacteria are fingerprint-like patterns which are highly reproducible and typical for different bacteria (Naumann, 1985; Naumann et al., 1988a, $b, 1990)$. They show broad and complex contours rather than distinct peaks (Naumann et al., 1988a). Essentially, this means that most of the information is 'hidden' beneath the shape of the spectrum. Since intact cells are tested, bacterial IR spectra are the very complex 'images' of the total chemical composition (proteins, membranes, cell wall, nucleic acids, etc.) of the cell. Owing to the multitude of cellular compounds, broad and superimposed absorbance bands are observed throughout the entire spectral range. Some of the bands can be assigned to distinct functional groups or chemical substructures, but we are still a long way from fully understanding the information content of the spectra. However, some spectral ranges are dominated by particular cell components and it is possible to subdivide the spectra into spectral windows

Abbreviations: FT-IR, Fourier-transform infrared spectroscopy; LPS, lipopolysaccharide; PHFA, poly- $\beta$-hydroxyfatty acid. which are considered to contain more specific information (Naumann et al., 1990).

The aim of the present study was to test whether FTIR can be used to group bacteria into IR spectral types or groups; whether a grouping which corresponds with conventional classifications can be obtained using specific parameterization; and whether a new spectrum displaying an unknown strain can be reliably identified to a known spectral class.

To classify spectra, a suitable quantitative measure of similarity or dissimilarity must be employed. This can be defined using correlation techniques (Shaps \& Sprouse, 1980) which consider the shapes or contours of the spectra rather than band numbers, frequencies or intensities. The spectral windows can subsequently be used to obtain the dissimilarity between each possible pair of spectra by calculating the correlation coefficient for a given window.

To demonstrate the potential of the FT-IR technique, we have developed classifications for some groups of bacteria. These examples include (1) the question whether bacteria can be allocated to the correct genus and species, (2) the possibilities of grouping bacteria according to only one single, distinct biological property, 
and (3) the possibility of detecting subtle differences within a population of very closely related organisms.

\section{Methods}

Strains and growth conditions. The strains used in this study were either from strain collections or were clinical isolates. To test the influence of the growth medium on spectral similarity, selected strains were grown on two different media. All strains were streaked onto agar plates using a four-quadrant streak pattern (Miller, 1982) unless otherwise stated. Enterobacteriaceae, Staphylococcus, Aeromonas and Pseudomonas strains were cultured on peptone agar plates. Some of the Pseudomonas strains ( $P$. aeruginosa ATCC 31156 and ATCC 10145 $)$ were also cultivated on CASO (casein peptone/soymeal peptone) agar plates (Merck). Streptococcus and some of the Staphylococcus strains (Staph. aureus DSM 20231 ${ }^{\mathrm{T}}$, Staph. hyicus DSM 20459 ${ }^{\mathrm{T}}$, Staph. saprophyticus DSM 20229' , Staph. xylosus DSM 20266 ${ }^{\mathrm{T}}$ and Staph. epidermidis DSM $20044^{\mathrm{T}}$ ) were grown on Columbia blood agar plates. Clostridium strains were grown on Columbia blood agar plates for $24 \mathrm{~h}$ in anaerobic jars (Anaerocult, Merck). The Legionella strains were plated on CYE (charcoal/yeast extract) agar plates and cultured for $5 \mathrm{~d}$. All strains were grown for $18 \mathrm{~h}$ unless otherwise stated; the temperature was $37 \pm 2{ }^{\circ} \mathrm{C}$.

Sources of strains. Clostridium strains and isolates were from the strain collection of one of us (G.S.). Streptococcal and staphylococcal isolates were a kind gift from I. Horbach, Robert Koch Institute of the Federal Health Office, Berlin. Stock strains and isolates of Legionella were a kind gift from D. G. Groothuis, Rijksinstituut voor Volksgezondheit en Milieuhygiëne, Bilthoven, the Netherlands. Escherichia coli isolates were a kind gift from L. Beutin, Robert Koch Institute of the Federal Health Office, Berlin. Other strains were kindly provided by F. Schumacher-Perdreaux, Hygiene-Institut der Universität zu Köln, Köln, FRG (Staphylococcus stock strains); E. Post, Schering AG, Berlin, (Pseudomonas strains); R. Stephan, Robert Koch Institute of the Federal Health Office, Berlin, (Salmonella isolates) and $\mathbf{R}$. Schubert, Hygiene-Institut, Frankfurt am Main, FRG (Aeromonas strains and isolates).

Media. The peptone agar contained $1 \%(\mathrm{w} / \mathrm{v})$ peptone (Merck), $1.4 \%$ (w/v) Lab-lemco powder (Oxoid) and was adjusted to $\mathrm{pH} 7.3$ prior to sterilization at $120^{\circ} \mathrm{C}$ for $45 \mathrm{~min}$. Casein peptone/soymeal peptone agar contained $1.5 \%(\mathrm{w} / \mathrm{v})$ casein peptone (tryptic), $0.5 \%$ soymeal peptone (papainic), $0.5 \% \mathrm{NaCl}$ and $1.5 \%$ (w/v) agar. The Columbia blood agar contained $3.9 \%(\mathrm{w} / \mathrm{v})$ Columbia agar base (Oxoid) and $5 \%$ $(\mathrm{v} / \mathrm{v})$ fresh blood from sheep. The charcoal/yeast extract agar consisted of $1 \%(\mathrm{w} / \mathrm{v})$ yeast extract (Difco), $0.2 \%$ charcoal (Sigma), $2 \%(\mathrm{w} / \mathrm{v})$ agar (Difco), $0.04 \%$ L-cysteine hydrochloride (Serva), 0.025\% Fe(III)pyrophosphate (Lohmann, Emmertal, FRG), 0.1\% 2-oxoglutarate (Lohmann) and was adjusted to $\mathrm{pH} 6.9$ prior to sterilization at $121^{\circ} \mathrm{C}$ for $15 \mathrm{~min}$.

Recording of the spectra. A small amount of late-exponential-phase cells (approx. 10-60 $\mu \mathrm{g}$ dry weight) was carefully removed with a platinum loop from confluent colonies in the third quadrant of the agar surface (this technique yielded the best reproducibility: Miller, 1982) and was suspended in $30 \mu \mathrm{l}$ distilled water. An aliquot $(25 \mu \mathrm{l})$ was transferred to a $\mathrm{ZnSe}$ (zinc-selenite) optical plate and dried under moderate vacuum between 2.5 and $7.5 \mathrm{kPa}$ to a transparent film suitable for absorbance/transmission FT-IR measurements. All spectra were recorded between $4000 \mathrm{~cm}^{-1}$ and $500 \mathrm{~cm}^{-1}$ (wavenumbers) on an IFS-48 FT-IR spectrometer (Bruker) equipped with an MCT (mercury-cadmium-telluride) detector by co-addition and averaging 256 scans: Spectral resolution was $8 \mathrm{~cm}^{-1}$. Data point resolution was approximately 1 point per wavenumber. The digitized spectra were stored on an auxiliary Aspect 1000 computer (Bruker) and were then transferred to a MicroVAX workstation 2000 computer (Digital Equipment) for further evaluation. To minimize problems arising from unavoidable base-line shifts and to enhance the resolution of superimposed bands, the smoothed first or second derivatives of the original spectra were calculated using a Savitzky-Golay algorithm (Savitzky \& Golay, 1964).

Spectral windows. A preselection of five spectral windows was done considering their specific information content and their discrimination power (Naumann et al., 1990):

(1) the window between 3000 and $2800 \mathrm{~cm}^{-1}\left(\mathrm{~W}_{1}\right.$; the 'fatty acid region I'), dominated by the $-\mathrm{CH}_{3},>\mathrm{CH}_{2}$ and $\equiv \mathrm{CH}$ stretching vibrations of the functional groups usually present in the fatty acid components of the various membrane amphiphiles;

(2) the window between 1800 and $1500 \mathrm{~cm}^{-1}\left(\mathrm{~W}_{2}\right.$; the amide region'), dominated by the amide I and amide II bands of proteins and peptides;

(3) the window between 1500 and $1200 \mathrm{~cm}^{-1}\left(\mathrm{~W}_{3}\right.$; the 'mixed region'), a spectral region containing information from proteins, fatty acids and phosphate-carrying compounds;

(4) the window between 1500 and $1400 \mathrm{~cm}^{-1}\left(\mathrm{~W}_{31}\right.$; the 'fatty acid region $\mathrm{II}^{\prime}$ ), a subrange of $\mathrm{W}_{3}$, dominated by the $-\mathrm{CH}_{3}$ and $>\mathrm{CH}_{2}$ bending vibrations of the same functional groups as expressed in $\mathrm{W}_{1}$;

(5) the window between 1200 and $900 \mathrm{~cm}^{-1}\left(\mathrm{~W}_{4}\right.$; the "polysaccharide region'), dominated by the fingerprint-like absorption bands of the carbohydrates present within the cell wall: and

(6) the window between 900 and $700 \mathrm{~cm}^{-1}\left(\mathrm{~W}_{5}\right.$; the 'true fingerprint') showing some remarkably specific spectral patterns, which are as yet unassigned to cellular components or to functional groups.

Parameterization of the spectral data. Since bacterial FT-IR spectra are fingerprint-like patterns which result from the superimposed absorbance bands of all constituents of the cell, and since there are no simple or a priori correlations between number, frequency, width and intensity of FT-IR peaks of a given biological compound and its microbiological significance, the elaboration of classifications on the basis of FT-IR spectra required parameterization of the spectral data. The appropriate grouping of bacterial spectra into clusters was achieved by systematically varying some parameters prior to cluster analysis. These parameters concerned the filtering of the spectra (first or second derivative), the selection and combination of certain spectral windows and their weighting. The weighting factors were intended to account for the specific contributions of some cellular compounds, e.g. fatty acids of the membrane or polysaccharides of the cell wall. According to the principles of the means-ends analysis of heuristic (Newell \& Simon, 1972), the parameters were systematically varied until the resulting classification agreed, by and large, with the desired classification which can be related to microbiological data.

Spectral similarity and cluster analysis. We used Pearson's product moment correlation coefficient as a measure of similarity between bacterial IR spectra (Shaps \& Sprouse, 1980). According to equation (1) the correlation coefficients were transformed to the so-called $d$-values or spectral distances (a measure of dissimilarity), which theoretically may adopt values between 0 and 2000 (Naumann, 1985). A spectral distance value between zero and 10 can be taken as an indication of identical or indistinguishable spectra, because spectra of one and the same strain, independently and repeatedly recorded over long periods of time using different batches of the same type of growth medium, typically showed mean distance values near 10 (Naumann et al., 1990). 
This corresponds to a correlation coefficient of 0.99 . The $d$-value or spectral distance is calculated as:

$$
d_{\mathrm{y} 1 \mathrm{y} 2}=\left(1.0-\mathrm{r}_{\mathrm{y} 1 \mathrm{y} 2}\right) \cdot 1000 \cdot 0
$$

Since the spectra were subdivided into several spectral windows, the similarity between two spectra was calculated as a linear weighted combination of the single similarities giving the mean or overall spectral similarity. The single similarities were transformed to a uniform scaling level, multiplied by the weights, co-added and divided by the sum of the weights.

For clustering, either UPGMA or Ward's algorithm was used. The only difference between the two methods is the way in which the distances between clusters are calculated following every fusion cycle (Späth, 1980). In UPGMA the distance is calculated as the unweighted average of the old distance values. In contrast, Ward's algorithm fuses those two clusters which yield the least increase of variance (heterogeneity) or error sum of squares within the new cluster and, therefore, will construct the most homogeneous groups. The variance or error sum of squares is calculated as the sum of the squared distances from each member of the cluster to the centre of the cluster (Ward, 1963).

All computations were performed on a MicroVAX workstation 2000 computer.

\section{Results}

For most of the taxa studied here, Ward's algorithm and UPGMA yielded similar results. However Ward's algorithm led to a clearer separation of the clusters by the minimization of the within-group variance. In some cases, the clusters achieved by Ward's algorithm were in better agreement with conventional classification schemes.

The results of cluster analyses are depicted in the form of dendrograms. In all cases, the left vertical axis of these dendrograms shows the fusion levels. In the case of UPGMA the left vertical axis is scaled by the 'spectral distance', and the right one by the 'similarity ratio', expressed in percent. However, in the case of Ward's algorithm the fusion levels are no longer spectral distances but depict increasing variance or heterogeneity. The magnitude of this heterogeneity depends to a large extent on the number of spectra in a cluster and the similarity between them. Therefore, only the dendrograms achieved by UPGMA are directly comparable to each other.

\section{FT-IR grouping according to the correct genus and identification of unknown spectra}

A data set of 39 spectra representing selected species of the genera Staphylococcus, Streptococcus and Clostridium was analysed (Fig. 1). Both Ward's algorithm and UPGMA yielded very similar results. All of the staphylococci tested formed a dense cluster which was subdivided into two subclusters containing the coagulase-positive and the coagulase-negative strains, respectively. Staph. hyicus was located in the coagulase-positive subcluster as expected, but was well separated from the Staph. aureus strains. Within the coagulase-negative subcluster, Staph. epidermidis and Staph. saprophyticus/xylosus strains were clearly separated at the $94 \%$ similarity level. Species clusters were formed for Staph. aureus and Staph. saprophyticus/xylosus at similarity levels of $97 \cdot 1 \%$ and $95.6 \%$, respectively. Interestingly, FT-IR did not differentiate between strains of Staph. saprophyticus and Staph. xylosus. These were originally described as a single species and show DNA-DNA binding of about $70 \%$ under optimal reassociation conditions (Kloos \& Schleifer, 1984). The two spectra of Staph. epidermidis DSM $20044^{\mathrm{T}}$, from bacteria grown on different media (Columbia blood agar and peptone agar, respectively), fused at a similarity level of $96.8 \%$ and were separated from Staph. epidermidis DSM 20042 and DSM 1798. The pairs of spectra of Staph. hyicus DSM 20459', Staph. aureus DSM 20231 ${ }^{\mathrm{T}}$ and Staph. xylosus DSM 20266 ${ }^{\mathrm{T}}$ cultured on peptone agar and Columbia blood agar showed fusion levels of $98.4 \%, 99.1 \%$ and $97.2 \%$ spectral similarity, respectively. Thus, growth on different media only slightly decreased the spectral similarity, since the typical value for repetitively measured spectra of a given strain grown on the same medium is $99 \%$ (Naumann $e t$ al., 1990).

The streptococcal strains formed a denser genus cluster $(95.2 \%$ similarity) than the staphylococcal strains $(91.5 \%$ similarity). Species clusters could be observed for Strep. faecalis, Strep. faecium and Strep. pyogenes at similarity ratios of $98.7 \%, 98.5 \%$ and $98.3 \%$, respectively. However, in spite of their taxonomic affiliation to cocci and to rods respectively, the genera Streptococcus and Clostridium could not be completely separated into two distinct genus clusters. Moreover, the relatedness between $C$. innocuum and Streptococcus was closer (about $94 \%$ ) than that between coagulase-positive and -negative staphylococci (about $92 \%$ similarity level). This is due to the fact that the classification schemes discussed in this study are based on spectral similarity alone and are influenced by the selected spectral windows.

To decide whether spectra of unknown bacteria would be identified when included in the analysis, 60 clinical isolates were tested. The first isolate ('unknown 1') was located in the Staph. aureus subcluster and was most closely related to Staph. aureus ATCC 6538 (99.1\% similarity). Another sample ('unknown 2') was found to belong to the Strep. faecium subcluster ( $98.9 \%$ similarity). In this way all 60 clinical isolates (36 staphylococci and 24 streptococci) were tested. All were correctly assigned to their respective species cluster at an average similarity ratio of $98.4 \% \pm 0.9 \%$ (Tables 1 and 2 ). 


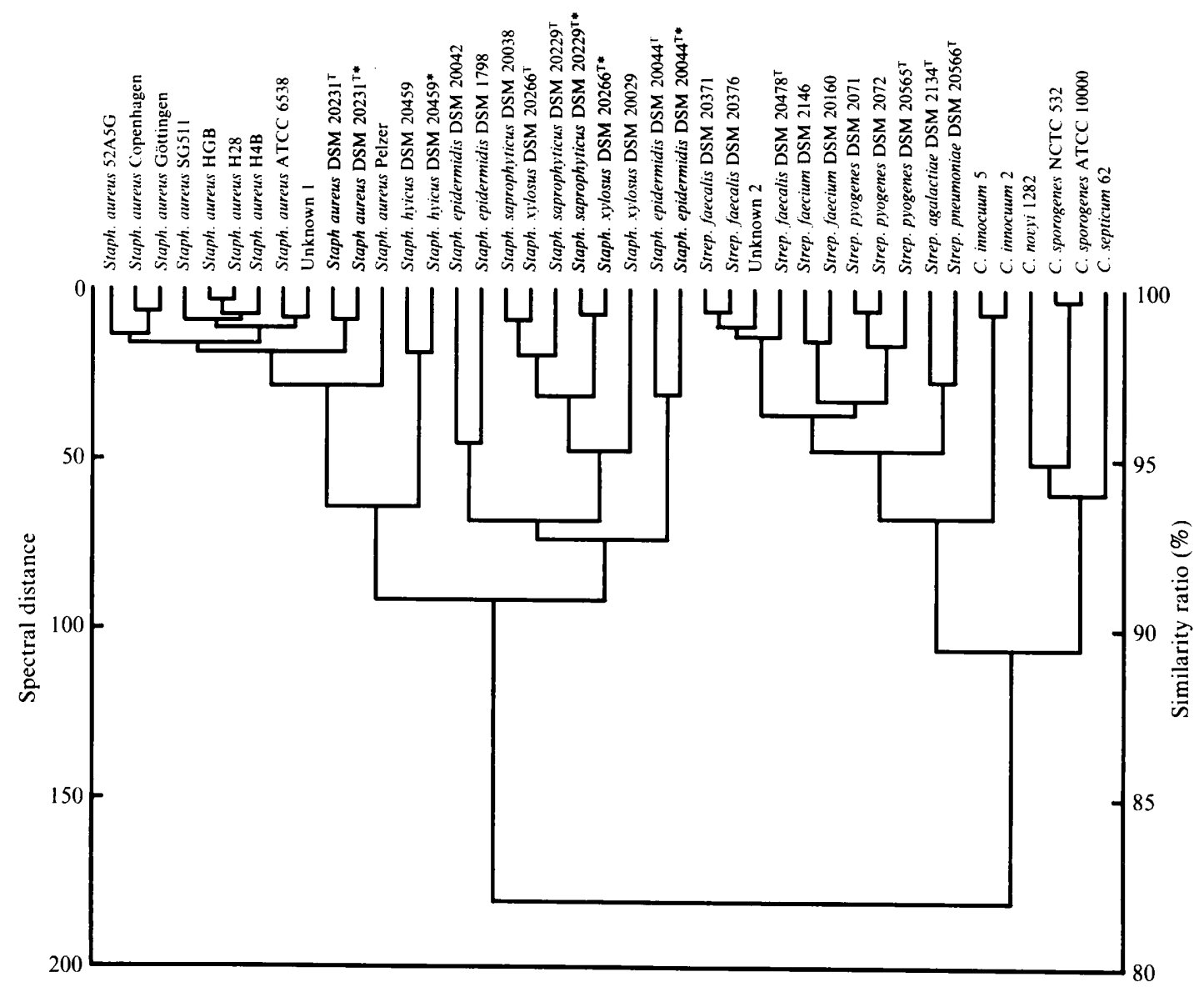

Fig. 1. Classification scheme for some specimens of the genera Staphylococcus, Streptococcus and Clostridium. Cluster analysis was performed using the first derivatives of the spectra considering the spectral ranges (weighting factors in parentheses) $3000-2800 \mathrm{~cm}^{-1}$ $(1 \cdot 0), 1200-900 \mathrm{~cm}^{-1}(3 \cdot 0)$ and $900-700 \mathrm{~cm}^{-1}(1 \cdot 0)$. The average linkage method (UPGMA) was applied. Staphylococcus strains which were grown on Columbia blood agar plates are marked by asterisks.

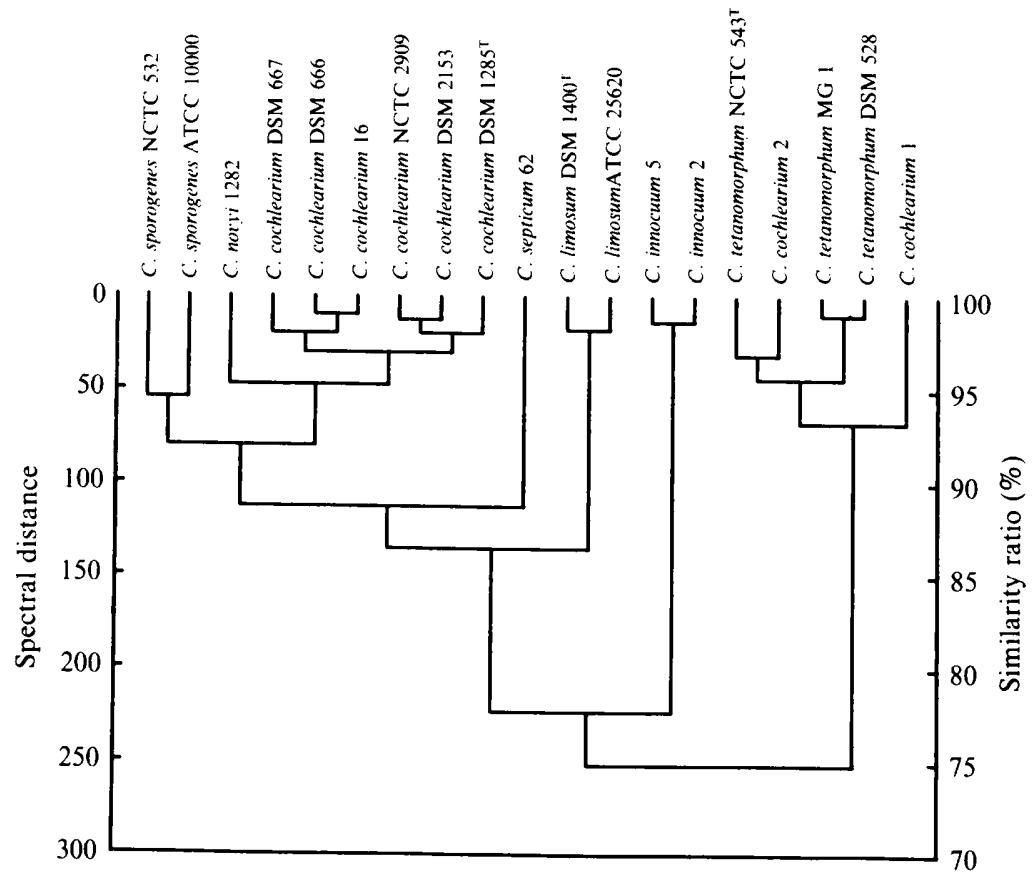

Fig. 2. Classification scheme for some specimens of the genus Clostridium. Cluster analysis was performed using the second derivatives of the spectra considering the spectral ranges (weighting factors in parentheses) $1200-900 \mathrm{~cm}^{-1}(2 \cdot 0)$ and $1500-1200 \mathrm{~cm}^{-1}(1.0)$ and applying the average linkage (UPGMA). 
Table 1. Clinical staphylococcal isolates which were identified by including them in an established cluster analysis

\begin{tabular}{|c|c|c|}
\hline Isolate & Nearest neighbour(s) & $\begin{array}{c}\text { Similarity } \\
(\%)\end{array}$ \\
\hline $495^{*}$ & Staph. aureus ATCC 6538 & $99 \cdot 1$ \\
\hline $237 \mathrm{~A}$ & Staph. aureus ATCC 6538 & $99 \cdot 3$ \\
\hline $328 \mathrm{~A}$ & Staph. aureus ATCC 6538 & $99 \cdot 1$ \\
\hline 335 & Staph. aureus DSM $20231^{\mathrm{T}}$ & $98 \cdot 6$ \\
\hline 345 & Staph. aureus ATCC 6538/SG 511 & 98.9 \\
\hline 367 & Staph. aureus DSM $20231^{\mathrm{T}}$ & $99 \cdot 3$ \\
\hline L374 & Staph. aureus DSM $20231^{\mathrm{T}}$ & $99 \cdot 3$ \\
\hline 402 & Staph. aureus ATCC 6538/SG 511 & $99 \cdot 0$ \\
\hline 410 & (within aureus subcluster) & $97 \cdot 7$ \\
\hline L445 & (within aureus subcluster) & $98 \cdot 7$ \\
\hline L449 & (within aureus subcluster) & $97 \cdot 1$ \\
\hline 475 & (within aureus subcluster) & $96 \cdot 8$ \\
\hline 480 & (within aureus subcluster) & $96 \cdot 5$ \\
\hline 482 & (within aureus subcluster) & $93 \cdot 4$ \\
\hline $485 \mathrm{~A}$ & (within aureus subcluster) & $97 \cdot 5$ \\
\hline 486 & Staph. aureus Copenhagen/Göttingen & $99 \cdot 1$ \\
\hline 495 & Staph aureus ATCC 6538 & $99 \cdot 1$ \\
\hline 507 & Staph. aureus Copenhagen/Göttingen & $98 \cdot 7$ \\
\hline M550 & Staph. aureus SG 511/ÄTCC 6538 & $98 \cdot 9$ \\
\hline M582 & Staph. aureus DSM $20231^{\mathrm{T}}$ & $98 \cdot 6$ \\
\hline L614 & (within aureus subcluster) & $98 \cdot 4$ \\
\hline L644 & Staph. aureus DSM $20231^{\mathrm{T}}$ & $98 \cdot 5$ \\
\hline L646 & Staph. aureus 52A5G & $98 \cdot 8$ \\
\hline L1423 & Staph. aureus DSM $20231^{\mathrm{T}}$ & $98 \cdot 5$ \\
\hline 2490 & Staph. aureus Copenhagen/Göttingen & $99 \cdot 0$ \\
\hline 2518 & Staph. aureus $\mathrm{HGB} / \mathrm{H} 28 / \mathrm{H} 4 \mathrm{~B}$ & $98 \cdot 9$ \\
\hline M2748 & (within aureus subcluster) & $98 \cdot 2$ \\
\hline M2971 & Staph. aureus SG 511 & $99 \cdot 3$ \\
\hline 3187 & Staph. aureus DSM $20231^{\mathrm{T}}$ & $99 \cdot 2$ \\
\hline 3201 & Staph. aureus $\mathrm{HGB} / \mathrm{H} 28 / \mathrm{H} 4 \mathrm{~B}$ & 98.9 \\
\hline 3279 & (within aureus subcluster) & $98 \cdot 2$ \\
\hline 3316 & Staph. aureus Copenhagen/Göttingen & $99 \cdot 0$ \\
\hline 3409 & Staph. aureus DSM $20231^{\mathrm{T}}$ & $99 \cdot 2$ \\
\hline 3456 & Staph. aureus DSM $20231^{\mathrm{T}}$ & $98 \cdot 4$ \\
\hline 3481 & Staph. aureus Pelzer & $98 \cdot 5$ \\
\hline $10 \cdot 87$ & Staph. aureus Copenhagen/Göttingen & $98 \cdot 8$ \\
\hline$\sum 36$ isolates & & $98 \cdot 5 \pm 2 \cdot 1$ \\
\hline
\end{tabular}

* This isolate is 'unknown l' in Fig. 1. For abbreviations see Table 3.

\section{Classification of Clostridium tetanomorphum and}

C. cochlearium strains

The classification of 12 spectra of different strains of the genus Clostridium yielded clusters that clearly correlated with the existing classification (Fig. 2). Species clusters were formed at different similarity levels for $C$. sporogenes $(94.5 \%), C$. cochlearium $(96.9 \%), C$. limosum $(98.0 \%), C$. innocuum $(98.6 \%)$ and C. tetanomorphum $(93.2 \%)$. Two single isolates affiliated to $C$. novyi and $C$. septicum, respectively, remained unclustered and well separated from the other species.

Furthermore, two isolates (strains 1 and 2), originally identified as $C$. cochlearium, were shown to be more closely related to $C$. tetanomorphum than to the $C$. cochlearium stock strains. The taxonomic status of $C$. tetanomorphum was considered to be doubtful, since the type strain did not exhibit the characteristics originally described for this species (Cato et al., 1986). Recently published data showed that the DNA-DNA homology values between $C$. cochlearium and $C$. tetanomorphum were only $10-19 \%$. On the basis of these results the classification of $C$. tetanomorphum as a valid species was suggested by the authors (Wilde et al., 1989). Obviously, our FT-IR classification performed independently on a selection of the same stock strains and the same isolates of clostridia lends support to the suggestion that $C$. cochlearium and $C$. tetanomorphum represent two distinctly separated species clusters.

\section{FT-IR grouping of Legionella strains according to the production of poly- $\beta$-hydroxyfatty acids}

Fifty strains, either clinical isolates or stock strains, belonging to the genus Legionella were cultured on CYE agar plates at $37^{\circ} \mathrm{C}$ for $5 \mathrm{~d}$ prior to measurements and analysis (Fig. 3). Visual examination of the spectra suggested the existence of two different types of Legionella spectra, with or without a number of strong extra bands in the range $1800-800 \mathrm{~cm}^{-1}$. In particular, the spectral range between 1200 and $900 \mathrm{~cm}^{-1}$, being typical for different Legionella strains (Horbach et al., 1988), was remarkably variable. Application of FT-IR subtraction techniques and comparison with literature data (Haynes et al., 1958; Rouf \& Stokes, 1962) proved these features to be caused by a poly- $\beta$-hydroxyfatty acid (PHFA). Fig. 4(a) shows spectra measured from two Legionella pneumophila serogroup 4 isolates which differed solely in their ability to produce this compound. Fig. $4(b)$ shows the difference spectrum obtained by digital subtraction techniques (spectrum 1 minus spectrum 2). This difference spectrum exhibits the typical absorption features of a polyester-like compound and shows remarkable similarity to that of poly- $\beta$-hydroxybutyric acid isolated from Bacillus megaterium and Sphaerotilus natans strains (Rouf \& Stokes, 1962).

The PHFA-like storage material was produced in considerable but varying amounts by some of the Legionella strains. Both cluster algorithms clearly separated the PHFA producers from the non-producers at a similarity ratio of about $63 \%$. Furthermore, the PHFA cluster was subdivided according to the degree of PHFA production. Thus, because of the large amount of PHFA produced by these three strains the $L$. pneumophila Rotterdam 29 isolate was located closer to $L$. rubrilucens ATCC $35304^{\mathrm{T}}$ and L. feeleii $691-\mathrm{WI}-\mathrm{H}$ than to other PHFA-producing $L$. pneumophila strains. All nonproducing L. pneumophila strains, with the exception of serogroup 1 strain Philadelphia, were located in a dense subcluster of about $91 \%$ similarity ratio (Fig. 3). 
Table 2. Clinical streptococcal isolates which were identified by including them in an established cluster analysis

\begin{tabular}{|c|c|c|}
\hline Isolate & Nearest neighbour(s) & $\underset{(\%)}{\text { Similarity }}$ \\
\hline L5H & Strep. faecalis DSM 20371/DSM 20376/DSM 20478 & $98 \cdot 0$ \\
\hline 120 & Strep. faecalis DSM 20371/DSM 20376/DSM 20478 & $97 \cdot 8$ \\
\hline 126 & Strep. faecalis DSM 20371/DSM 20376/DSM 20478 & $\mathbf{9 7 \cdot 7}$ \\
\hline 127 & Strep. faecalis DSM 20371/DSM 20376/DSM 20478 & $97 \cdot 7$ \\
\hline L144 & Strep. faecalis DSM 20371/DSM 20376 & $98 \cdot 6$ \\
\hline 208 & Strep. faecalis DSM $20478^{\mathrm{T}}$ & $98 \cdot 8$ \\
\hline 217 & Strep. faecalis DSM 20371/DSM 20376 & $98 \cdot 6$ \\
\hline 220 & Strep. faecalis DSM 20371/DSM 20376 & $98 \cdot 5$ \\
\hline 230 & Strep. faecalis DSM 20371/DSM 20376/DSM 20478 & $98 \cdot 1$ \\
\hline 238 & Strep. faecalis DSM 20371/DSM 20376/DSM 20478 & 97.9 \\
\hline 262 & Strep. faecalis DSM 20371/DSM 20376/DSM 20478 & $97 \cdot 7$ \\
\hline 267 & Strep. faecalis DSM 20371/DSM 20376 & 98.8 \\
\hline 294 & Strep. faecalis DSM 20371/DSM 20376 & $99 \cdot 0$ \\
\hline L376 & Strep. faecalis DSM 20371/DSM 20376 & $99 \cdot 0$ \\
\hline 467 & Strep. faecalis DSM 20371/DSM 20376/DSM 20478 & $97 \cdot 4$ \\
\hline 490 & Strep. faecalis DSM 20371/DSM 20376 & $98 \cdot 8$ \\
\hline 515 & Strep. faecalis DSM 20371/DSM 20376/DSM 20478 & $98 \cdot 2$ \\
\hline 2165 & Strep. faecalis DSM 20371/DSM 20376 & $98 \cdot 7$ \\
\hline 3104 & Strep. faecalis DSM 20371/DSM 20376 & 98.6 \\
\hline $3379^{*}$ & Strep. faecalis DSM 20371/DSM 20376 & 98.9 \\
\hline 3433 & Strep. faecalis DSM 20371/DSM 20376 & $98 \cdot 8$ \\
\hline 3504 & Strep. faecalis DSM 20371/DSM 20376/DSM 20478 & $97 \cdot 2$ \\
\hline L4682 & Strep. faecalis DSM 20371/DSM 20376 & $98 \cdot 7$ \\
\hline $\mathbf{H}$ & Strep. faecalis DSM 20371/DSM 20376/DSM 20478T & $98 \cdot 0$ \\
\hline$\sum 24$ isolates & & $98 \cdot 4 \pm 0.5$ \\
\hline
\end{tabular}

* This isolate is 'unknown 2' in Fig. 1. For abbreviations see Table 3.

Different spectral windows emphasize different aspects of a given data set, as different binary coefficients (simple matching coefficient, Jaccard's coeffcient, etc.) do in numerical taxonomy (Sneath, 1984). Therefore, it is obvious that one cannot define a 'correct' combination of spectral windows suitable for any problem. For example, the grouping of the Legionella strains shown in Fig. 3 in relation to the PHFA production could also be achieved in accordance to the correct species level using other spectral windows (unpublished results; see also Horbach et al., 1988).

\section{Grouping bacteria according to the presence of an outer membrane}

A data set of 139 different spectra comprising stock strains as well as clinical isolates affiliated to the genera Staphylococcus, Streptococcus, Clostridium, Aeromonas, Pseudomonas and Legionella, and to the family Enterobacteriaceae, was investigated (Fig. 5). The specimens used for this analysis are listed in Table 3 . The spectra were grouped primarily according to the presence of an outer membrane (to obtain a separation which corresponds to the Gram stain reaction) and secondarily according to the genera. Thus, those spectral ranges which are mainly dominated by the fatty acid chains of the membrane amphiphiles were given priority. Ward's method formed two major clusters, which exclusively contained the Gram-positive and Gram-negative strains, respectively. There were four main subclusters, which were mainly associated with the genera under study, giving a total of seven groups or spectral types by further division of the Staphylococcus and Clostridium cluster. The first cluster ('STAPH.' in Fig. 5) assembled the 29 staphylococcal strains and was subdivided into three subclusters which showed variances of 107, 70 and 93, respectively. All 13 streptococci were located within the second cluster ('STREP.' in Fig. 5), which also contained the two Clostridium innocuum isolates. The Streptococcus cluster was more homogeneous (variance of 181) than the Staphylococcus cluster (variance of 307). This was not only caused by the larger number of spectra but also by the greater diversity in the staphylococcal spectra. The third cluster ('CLOST.' in Fig. 5) was formed by all Clostridium strains with the exception of the $C$. innocuum and $C$. bifermentans isolates. $C$. cochlearium and $C$. tetanomorphum spectra were also separated (cf. Fig. 2). According to the lowest similarity, the last fusion within the Clostridium cluster occurred at a variance of 284 . The two $C$. bifermentans isolates formed a distinct cluster 


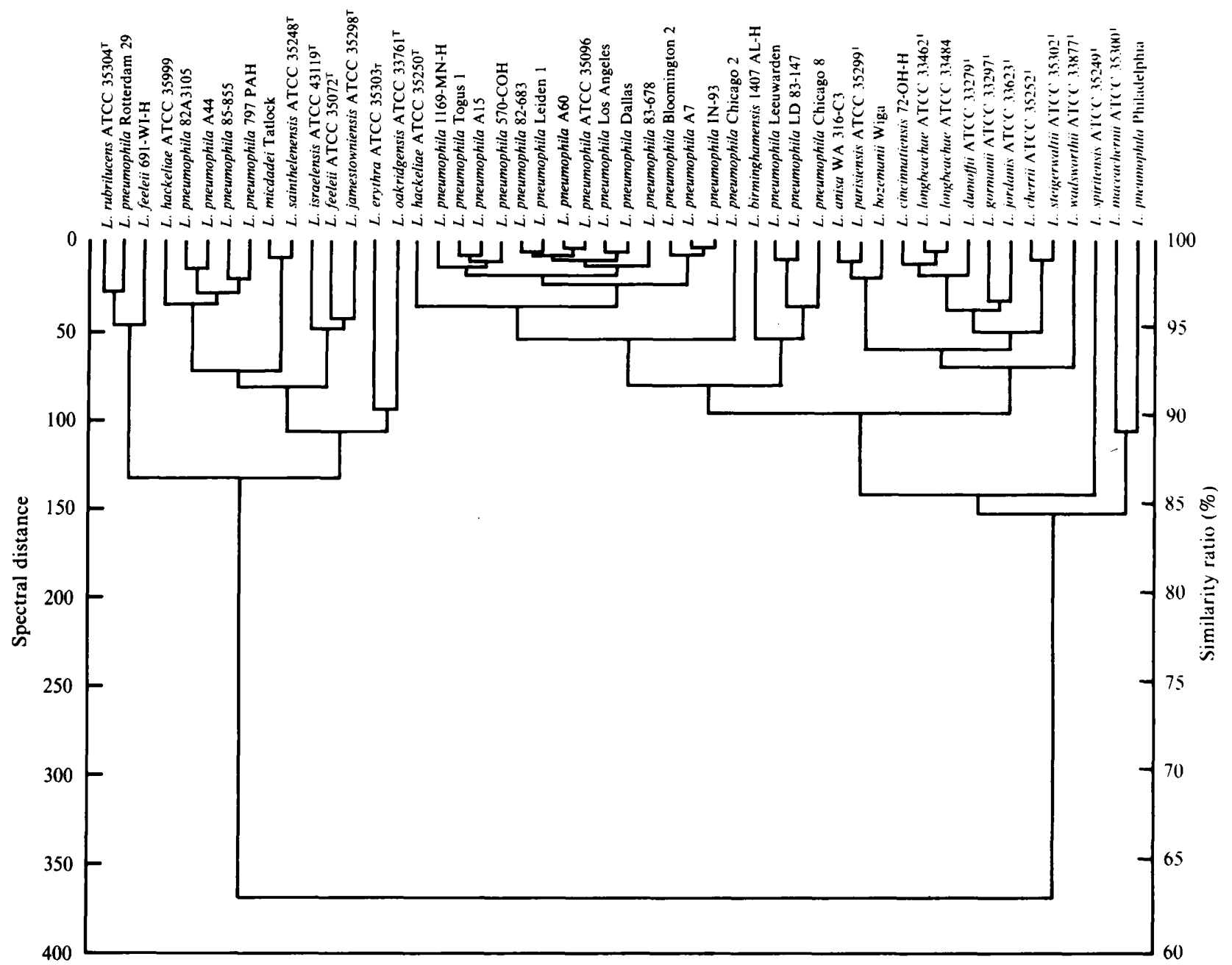

Fig. 3. Classification scheme for some specimens of the genus Legionella. Cluster analysis was performed using the first derivatives of the spectra considering the spectral range (window) $1200-900 \mathrm{~cm}^{-1}$ and applying the average linkage (UPGMA).

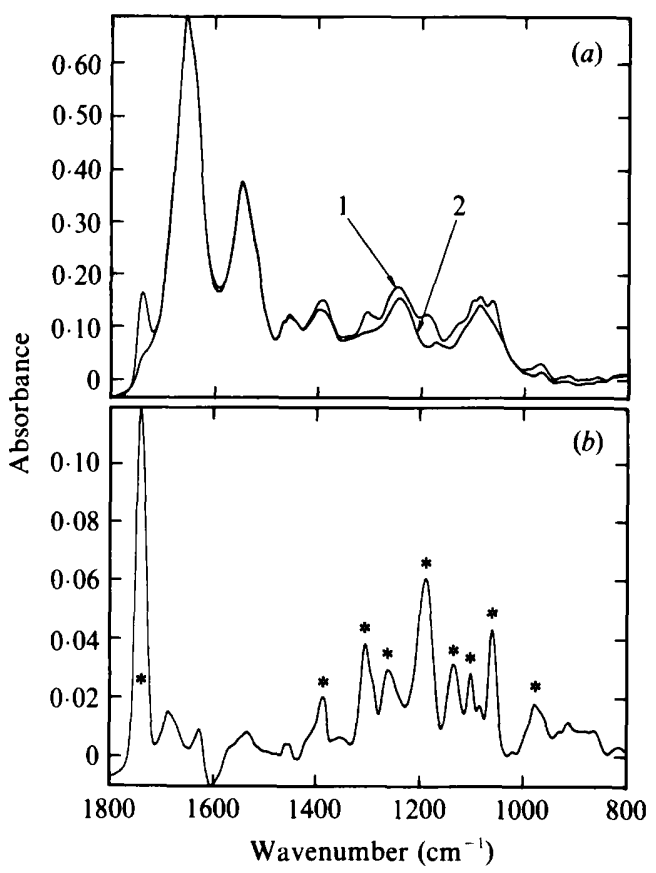

which was clearly separated from all other spectra within the Gram-positive major cluster. Furthermore, UPGMA separated $C$. bifermentans from all other Gram-positive and Gram-negative bacteria (data not shown). Comparison with IR spectra of Bacillus megaterium (Norris \& Greenstreet, 1958) suggested the formation of endospores by $C$. bifermentans under our culture conditions. At a variance of 2336 , all clusters containing Grampositive bacteria were fused. Thus, the Gram-positive strains composed a less dense cluster than the Gramnegative bacteria, which showed more homogeneity (Fig. 5).

The Gram-negative major cluster was subdivided into four subclusters, corresponding to the taxa Aeromonas/ Pseudomonas, Legionella, Salmonella and other Enterobacteriaceae, respectively. The first subcluster ('PSEUDO.'

Fig. 4. (a) Typical bacterial FT-IR spectra of PHFA-producing (1) and non-producing (2) Legionella pneumophila serogroup 4 strains. (b) Difference spectrum ( 2 minus 1 ); the absorption bands marked by asterisks are diagnostic for the polyester compound PHFA. 


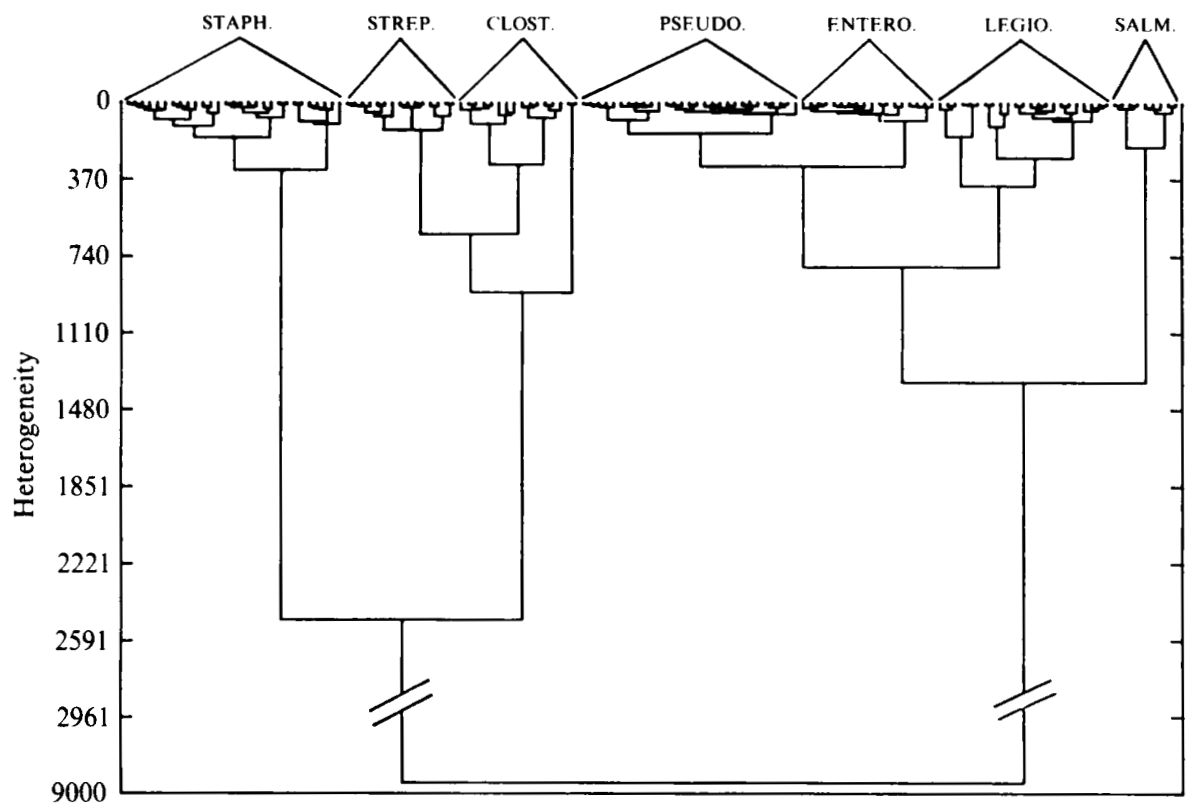

Fig. 5. Classification of different Gram-positive and Gram-negative bacteria. For identities of strains see Table 3. Cluster analysis was performed using the first derivatives of the spectra considering the spectral ranges (windows) $3000-2800 \mathrm{~cm}^{-1}, 1500-1400 \mathrm{~cm}^{-1}$ and $1200-900 \mathrm{~cm}^{-1}$. All three ranges were equally weighted. Ward's algorithm was applied.

Table 3. List of the specimens displayed in Fig. 5

The order of this list corresponds to the order in the dendrogram; the first name is the leftmost element in Fig. 5 and the last name is the rightmost one. Repetitively measured spectra of some specimens have been included for control purposes. (The names of the clusters refer to Fig. 5; for details see text.)

Cluster 'sTAPH.'

First subcluster

Staph. aureus 52A5G

Staph. aureus Copenhagen

Staph. aureus HGB

Staph. aureus Pelzer

Staph. xylosus DSM 20266 ${ }^{\mathrm{T}}$

Staph. carnosus DSM 20501

Staph. aureus SG 511

Staph. aureus DSM 20231

Staph. simulans DSM $20322^{\mathrm{T}}$

Staph. haemolyticus DSM $20263^{\mathrm{T}}$

Staph. epidermidis DSM 20044

Staph. gallinarum DSM $20610^{\mathrm{T}}$

Staph. chromogenes DSM $20454^{\mathrm{T}}$

Second subcluster

Staph. epidermidis DSM 20042

Staph. epidermidis KH 11

Staph. capitis K3

Staph. intermedius DSM 20373

Staph. haemolyticus BP9

Staph. warneri DSM 20316

Staph. hominis R163

Staph. hyicus 48

Staph. hyicus DSM 20459T

Third subcluster

Staph. saprophyticus DSM 20038

Staph. saprophyticus DSM 20229T

Staph. xylosus DSM 20029

Staph. capitis DSM 20326

Staph. cohnii DSM 20260

Staph. kloosii DSM 20676

Staph. hominis DSM $20328^{\mathrm{T}}$
Cluster 'STREP.'

Strep. faecalis DSM 20371

Strep. faecalis DSM 20376

Strep. liquefaciens 534

Strep. faecalis DSM 20478'

Strep. faecium DSM 2146

Strep. faecium DSM 20160

Strep. faecium DSM $20477^{\mathrm{T}}$

Strep. pyogenes DSM 2071

Strep. pyogenes DSM 2072

Strep. pyogenes DSM 20565

Strep. $\beta$-haemolytic group A 528

Strep. agalactiae DSM $2134^{\mathrm{T}}$

Strep. pneumoniae DSM $20566^{\top}$

C. innocuum 5

C. innocuum 2

Cluster 'Clost.'

First subcluster

C. novyi 1282

C. cochlearium DSM 666

C. cochlearium DSM 667

C. malenominatum DSM $1127^{\mathrm{T}}$

C. malenominatum ATCC $25776^{\mathrm{T}}$

C. septicum 62

C. sporogenes ATC 10000

C. limosum DSM $1400^{\top}$

Second subcluster

C. tetanomorphum NCTC $543^{\mathrm{T}}$

C. tetanomorphum NCTC $543^{\mathrm{T}}$ (control)

C. malenominatum 5

C. tetanomorphum DSM 528

C. cochlearium 2

C. cochlearium 1 
Table 3-continued

Unclustered Clostridium strains

C. bifermentans Berlin

C. bifermentans 87

Cluster 'PSEuDo.'

First subcluster

A. punctata NCMB 74

A. hydrophila 218

A. hydrophila 212

A. hydrophila 316

A. punctata BPE 113

Second subcluster

Ps. aeruginosa ATCC 10145'

Ps. aeruginosa ATCC 15442

Ps. aeruginosa ATCC 19142

Ps. aeruginosa ATCC 21776

Ps. aeruginosa ATCC 31482

Ps. aeruginosa ATCC 31156

Third subcluster

Ps. aeruginosa ATCC 9027

Ps. aureofaciens ATCC $13985^{\mathrm{T}}$

Ps. aeruginosa ATCC 9721

Ps. fluorescens biotype B ATCC 17482

Ps. fluorescens biotype C ATCC 17400

Ps. citronellolis ATCC $13674^{\top}$

Ps. chlororaphis ATCC 9446

Ps. citronellolis ATCC $13674^{\mathrm{T}}$ (control)

Ps. fluorescens ATCC $13525^{\mathrm{T}}$

Ps. syringae ATCC $19310^{\mathrm{T}}$

Ps. aureofaciens ATCC $13985^{\top}$

Ps. fluorescens biotype G ATCC 17573

Ps. putida ATCC $12633^{\mathrm{T}}$

Ps. aeruginosa ATCC 31156 (control, grown on CASO)

Ps. aeruginosa ATCC $10145^{\mathrm{T}}$ (control, grown on CASO)

Ps. aeruginosa ATCC 13388

Ps. aeruginosa ATCC 14502

Ps. diminuta ATCC $11568^{\mathrm{T}}$

Cluster 'ENTERO.'

Proteus mirabilis DSM 788

Proteus vulgaris DSM 2140

Proteus tulgaris DSM 33420

Providencia rettgerii ATCC $29944^{\mathrm{T}}$

Proteus morganii DSM 30117

Serratia liquefaciens ATCC 35551

Providencia alcalifaciens ATCC 25828

Providencia rettgerii ATCC 25932

Serratia marcescens DSM $30121^{\mathrm{T}}$
Klebsiella pneumoniae DSM 681

Providencia stuartii DSM 2250

Providencia stuartii DSM 2250 (control)

Serratia liquefaciens ATCC 27592

Providencia stuartii ATCC $25827^{\mathrm{T}}$

Serratia liquefaciens DSM 30063

Hafnia alvei $231 / 87$

Edwardsiella tarda DSM $30052^{\mathrm{T}}$

Hafnia alvei DSM $30163^{\mathrm{T}}$

Cluster 'LEGIo.'

First subcluster

L. feeleii ATCC $35072^{\mathrm{T}}$

L. feeleii ATCC $35072^{\mathrm{T}}$ (control)

L. feeleii 691-WI-H

L. micdadei Tatlock

L. micdadei Tatlock (control)

L. sainthelenensis ATCC $35248^{\mathrm{T}}$

Second subcluster

L. maceachernii ATCC $35300^{\mathrm{T}}$

L. maceachernii ATCC $35300^{\mathrm{T}}$ (control)

L. pneumophila Philadelphia

L. pneumophila A15

Third subcluster

L. parisiensis ATCC $35299^{\top}$

L. bozemani $1 \mathrm{Wiga}$

L. gormanii ATCC $33297^{\top}$

L. dumoffii ATCC $33279^{\mathrm{T}}$

L. longbeachae ATCC $33462^{\top}$

L. jamestowniensis ATCC $35298^{\mathrm{T}}$

L. cherrii ATCC $35252^{\mathrm{T}}$

L. steigerwaltii ATCC $35302^{\mathrm{T}}$

L. spiritensis ATCC $35249^{\mathrm{T}}$

L. pneumophila Los Angeles

L. cincinnatiensis $72-\mathrm{OH}-\mathrm{H}$

L. cherrii ATCC $35252^{\mathrm{T}}$ (control)

L. steigerwaltii ATCC $35302^{\mathrm{T}}$ (control)

Cluster 'SALM.'

S. dublin $883 / 83$

S. dublin 1116/83

S. dublin 1451/83

S. dublin $364 / 84$

$S$. arizonae $488 / 83$

$S$. arizonae $63 / 85$

$S$. arizonae $702 / 83$

S. typhimurium $432 / 86$

S. typhimurium $473 / 86$

Abbreviations: T, type strain; ATCC, American Type Culture Collection, Rockville, MD, USA; DSM, Deutsche Sammlung von Mikroorganismen, Braunschweig, FRG; NCMB, National Collection of Marine Bacteria, Aberdeen, UK; NCTC, National Collection of Type Cultures, London, UK.

in Fig. 5) was composed of 5 Aeromonas and 24 Pseudomonas spectra. Further subdivision of this cluster revealed three subclusters showing variances of 19,36 and 53, respectively. The first of these subclusters contained only the A.punctata and A. hydrophila strains, whereas the second subcluster was formed by some strains of $P$. aeruginosa, grown on peptone agar. All remaining Pseudomonas strains were fused within the third subcluster. Some of the $P$. aeruginos $a$ strains found within the second subcluster were transferred to the third one when they were grown on CASO instead of peptone agar (cf. list of specimens in Table 3). The second, poorly structured, Gram-negative subcluster ('ENTERO.' in Fig. 5) contained 18 spectra out of the family Enterobacteriaceae, comprising Proteus, Providencia, Serratia, Klebsiella, Hafnia and Edwardsiella strains. From a spectroscopic point of view, many members of the Enterobacteriaceae, with the exception of the salmonellae, seem to be very similar. In several cases they show spectral distances from each other even lower than, or equal to those of repetitive measurements of the same strain. The last fusion within this cluster occurred at a variance of 


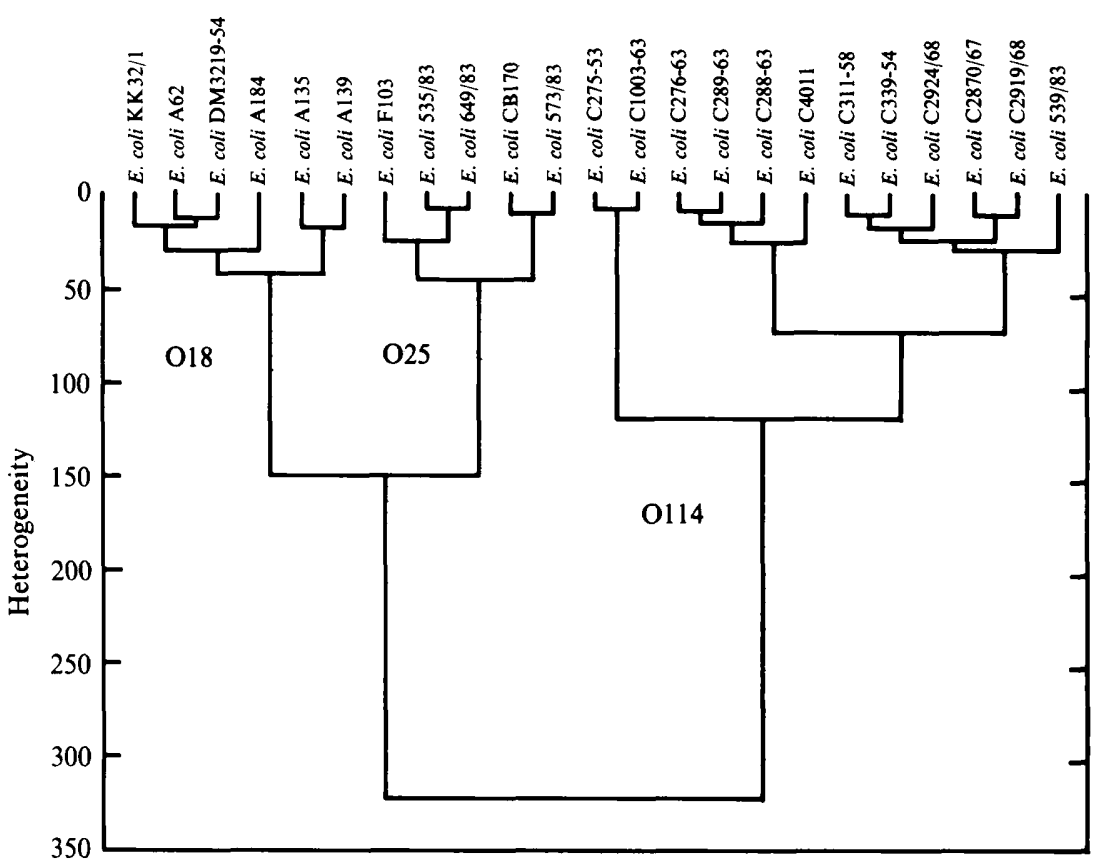

Fig. 6. Classification of selected isolates of the species Escherichia coli. Cluster analysis was performed using the first derivatives of the spectra considering the spectral ranges (windows) 1200 $900 \mathrm{~cm}^{-1}$ and $900-700 \mathrm{~cm}^{-1}$ and applying Ward's algorithm. Both spectral ranges were equally weighted.
79. The Enterobacteriaceae and the Aeromonas/Pseudomonas clusters were fused at 294. The third Gramnegative sub-cluster ('LEGIO.' in Fig. 5) assembled all 23 Legionella strains within this analysis at a fusion level of 380. Further subdivision of the Legionella cluster yielded three subclusters with variances of 152, 107 and 83, respectively. The first of these contained six specimens producing large amounts of a polyester compound (probably a PHFA); the second exclusively contained two $L$. maceachernii strains and two $L$. pneumophila strains. All remaining Legionella strains were located in the last subcluster. For control purposes, five of the spectra were replicate measurements. Three of these replicates (L. feeleii ATCC $35072^{\mathrm{T}}, L$. micdadei Tatlock and $L$. maceachernii ATCC $35300^{\mathrm{T}}$ ) were grouped in such a way that they were most related to each other; $L$. cherrii ATCC $35252^{\mathrm{T}}$ and L. steigerwaltii ATCC $35302^{\mathrm{T}}$ were recovered in the same subcluster (cf. Fig. 5 and list of the specimens in Table 3). At a variance of 745 the Legionella and the Pseudomonas/Enterobacteriaceae group were fused. The fourth Gram-negative subcluster, which was well separated from all other Gram-negative clusters, contained only the Salmonella dublin, $S$. arizonae and $S$. typhimurium isolates.

\section{Grouping of Escherichia coli isolates according to their $O$-antigenic structure}

The purpose of this analysis was to group 23 spectra of $E$. coli isolates according to their $\mathrm{O}$-antigenic properties. $\mathrm{O}$ antigens were determined by serological and LPS-gel electrophoresis techniques (Beutin et al., 1990). Since it was expected that differences in O-specific side chains of LPS would primarily be expressed in that spectral range where the polysaccharides dominate the observed spectral features, only the range between 1200 and $700 \mathrm{~cm}^{-1}$ was used for this cluster analysis. Using Ward's algorithm three distinct clusters were obtained, containing the O18, $\mathrm{O} 25$ and $\mathrm{O} 114$ strains, respectively (Fig. 6).

UPGMA formed four distinct clusters in such a way that the 018 and the $\mathrm{O} 25$ cluster were more closely related $(95.7 \%$ similarity) than the two 0114 clusters (94.8\% similarity) (data not shown).

\section{Discussion}

FT-IR spectroscopy can classify bacteria at different levels of taxonomic discrimination without any preselection of strains by other taxonomic criteria. In contrast to one-dimensional polyacrylamide gel electrophoresis (PAGE) and DNA-DNA hybridization (Jackman, 1987), FT-IR is useful at the serogroup (Fig. 6), species (Figs 1, 2) and genus level (Figs 1, 5). Data acquisition is faster than in PAGE and other techniques: with our present operating conditions, which are not yet optimal, recording of 100 spectra, transfer of data to the computer, data evaluation and cluster analysis can all be performed within $2 \mathrm{~d}$. Preparation is simple and quick, since only $10-60 \mu \mathrm{g}$ of biomass is required and no cell breakage and purification steps are involved. In contrast 
to classical tests and chemotaxonomy, FT-IR can be applied to all groups of bacteria. Patterns obtained by FT-IR are related to all cell constituents rather than to a single class of compounds as in e.g. PAGE.

We consider FT-IR spectroscopy and cluster analysis of bacterial cells to be a promising tool not only for identification and classification purposes based upon bacterial IR spectra alone, but also as an additional aid to support conventional methods for clarifying relationships, especially within poorly classified taxa. FT-IR can also reveal structures not detectable at once by other methods, e.g. the production of a storage compound by some Legionella strains. Bacterial FT-IR spectra display the entire chemical composition of the cell and, therefore, spectroscopic characterization of bacteria has to place reliance on a multitude of characters. Naturally, the taxonomic importance of a cellular component must not be directly correlated with the magnitude of its spectral expression. Certain cellular compounds like, for example, PHFA, may strongly influence the spectrum. Therefore, like other accepted and useful classification schemes, the data elaborated by FT-IR spectroscopy cannot per se reveal the natural order or even the phylogenetic relationships within a taxon. However, since all chemical compounds of the bacterial cell are an expression of a smaller or greater part of the genome, the spectra show in some way a phenetic and a genetic fingerprint of the strain under study.

It can be shown that selection of spectral ranges (windows) and specific parameterization of the data prior to cluster analysis enables the elaboration of classification schemes which are similar to those achieved by conventional methods. Classifications obtained by our method have proved to be practically sound, because clinical isolates can be securely assigned to the correct species cluster when they are included in an established cluster analysis. FT-IR spectroscopy can also shed light on the crucial problems arising with the classification of poorly classified taxa, such as Clostridium tetanomorphum, where our results support biochemical and microbiological findings. Furthermore, FT-IR spectroscopy allows the rapid and time-saving determination of some particular microbiological features such as PHFA production, $\mathrm{O}$-antigenic properties and the existence of an outer membrane, which is correlated with the Gram staining reaction.

This study was supported by a grant from the Ministry of Research and Technology of the Federal Republic of Germany. We thank Mrs Andrea Stäuble for excellent technical assistance and Mrs Siedy Sällström Baum for proofreading the typescript.

\section{References}

Beutin, L., Ørskov, I., Ørskov, F., Zimmermann, S., Prada, J., Gelderblom, H., Stephan, R. \& Whittam, T. S. (1990). Diversity of clonal types and virulence factors in strains of Escherichia coli belonging to the classical enteropathogenic (EPEC) O-serogroup 114. Journal of Infectious Diseases (in the Press).

Cato, E. P., George, W. L. \& Finegold, S. M. (1986). Genus Clostridium Prazmowski 1880, 23 AL. In Bergey's Manual of Systematic Bacteriology, vol. 2, pp. 1141-1200. Edited by P. H. A. Sneath, N. S. Mair, M. E. Sharpe \& J. G. Holt. Baltimore: Williams \& Wilkins.

Haynes, W. C., Melvin, E. H., Locke, J. M., Glass, C. A. \& Senti, F. R. (1958). Certain factors affecting the infrared spectra of selected microorganisms. Applied Microbiology 6, 298-304.

Horbach, I., NaumanN, D. \& Fehrenbach, F. (1988). Simultaneous infections with different serogroups of Legionella pneumophila investigated by routine methods and Fourier-Transform infrared spectroscopy. Journal of Clinical Microbiology 26, 1106-1110.

JACKMAN, P. J. H. (1987). Microbial systematics based on electrophoretic whole-cell protein patterns. Methods in Microbiology 19, 209-225.

Kloos, W. E. \& Schleifer, K. H. (1984). Genus IV. Staphylococcus Rosenbach 1884, 18 AL, (Nom. Cons. Opin. 17 Jud. Comm. 1958, 153). In Bergey's Manual of Systematic Bacteriology, vol. 2, pp. 10131035. Edited by P. H. A. Sneath, N. S. Mair, M. E. Sharpe \& J. G. Holt. Baltimore: Williams and Wilkins.

MiLleR, L. T. (1982). A single derivatization method for bacterial fatty acid methyl esters including hydroxy acids. Journal of Clinical Microbiology 16, 584-586.

NAUMANN, D. (1985). The ultra rapid differentiation and identification of pathogenic bacteria using FT-IR techniques. In SPIE, Fourier and Computerized Infrared Spectroscopy, vol. 553, pp. 268-269. Edited by J. G. Grasselli \& D. G. Cameron. Bellingham, WA: International Society for Optical Engineering.

Naumann, D., FiJala, V., Labischinski, H. \& Giesbrecht, P. (1988a). The differentiation and identification of pathogenic bacteria using FT-IR and multivariate statistical analysis. Mikrochimica Acta 1, 373-377.

Naumann, D., Fijala, V., Labischinski, H. \& Giesbrecht, P. (1988 $b$ ). The rapid differentiation and identification of pathogenic bacteria using Fourier Transform infrared spectroscopic and multivariate statistical analysis. Journal of Molecular Structure 174, 165-170.

NaumanN, D., Labischinski, H. \& Giesbrecht, P. (1990). The characterization of microorganisms by Fourier-Transform infrared spectroscopy (FT-IR). In Modern Techniques for Rapid Microbiological Analysis. Edited by W. H. Nelson, Weinheim \& New York: VCH Verlag Chemie (in the Press).

Newell, A. \& Simon, H. A. (1972). Logic: Task Analysis. In Human Problem Solving, pp. 416-454. Englewood Cliffs, NJ : Prentice-Hall.

Norris, K. P. \& Greenstreet, J. E. S. (1958). On the infrared absorption spectrum of Bacillus megaterium. Journal of General Microbiology 19, 566-580.

Rouf, M. A. \& Stokes, J. L. (1962). Isolation and identification of the sudanophilic granules of Sphaerotilus natans. Journal of Bacteriology 83, 343-347.

Savitzky, A. \& Golay, M. J. E. (1964). Smoothing and differentiation of data by simplified least squares procedures. Analytical Chemistry 36, $1627-1633$.

Shaps, R. H. \& SPRouse, J. F. (1980). Automated infrared spectra search and display. European Spectroscopy News 32, 39-42.

SNEATH, P. H. A. (1984). Numerical taxonomy. in Bergey's Manual of Systematic Bacteriology, vol. 1, pp. 5-7. Edited by N. R. Krieg \& J. G. Holt. Baltimore: Williams \& Wilkins.

Späth, H. (1980). Cluster Analysis Algorithms for Data Reduction and Classification of Objects. Chichester: Ellis Horwood.

WARD, J. H. (1963). Hierarchical grouping to optimize an objective function. Journal of the American Statistical Association 58, 236-244.

Wilde, E., Hippe, H., Tosunoglu, N., Schallehn, G., Herwig, K. \& GotTSCHALK, G. (1989). Clostridium tetanomorphum sp. nov., nom. rev. International Journal of Systematic Bacteriology 39, 127-134. 